\title{
Bone metastases affect prognosis but not effectiveness of third-line targeted therapies in patients with metastatic renal cell carcinoma
}

\author{
Roberto lacovelli, MD;" Daniele Santini, MD;" Mimma Rizzo, MD; ${ }^{*}$ Alessandra Felici, MD;* \\ Matteo Santoni, MD; ${ }^{*}$ Elena Verzoni, MD; ${ }^{*}$ Cristina Masini, MD; ${ }^{*}$ Francesco Massari, MD; \\ Nicola Calvani, MD; ${ }^{*}$ Alessandra Mosca, MD; Giuseppe Procopio, $\mathrm{MD}^{+}$
}

"Department of Radiology, Oncology and Human Pathology, Sapienza University of Rome, Rome, Italy; ‘Fondazione IRCCS Istituto Nazionale Tumori, Division of Medical Oncology, Rome, Italy

Cite as: Can Urol Assoc J 2015;9(7-8):263-7. http://dx.doi.org/10.5489/cuaj.2377

Published online August 10, 2015.

\section{Abstract}

Introduction: Treatment of metastatic renal cell carcinoma (mRCC) has improved with the use of targeted therapies, but bone metastases continue to be negative prognostic factor.

Methods: Patients with mRCC treated with everolimus (EV) or sorafenib (SO) after two previous lines of targeted therapies were included in the analysis. Overall survival (OS) and progressionfree survival (PFS) were assessed based on the presence of bone metastases and type of therapy; they were also adjusted based on prognostic criteria.

Results: Of the 233 patients with mRCC, 76 had bone metastases. Of the 233 patients, EV and SO were administered in 143 and 90 patients, respectively. Median OS was 10.4 months in patients with BMs and 17.4 months in patients without bone metastases $(p=0.002)$. EV decreased the risk of death by $18 \%$ compared to SO (adjusted hazard ratio [HR] 0.82, 95\% confidence interval [Cl] 0.74-0.91; $p<0.001)$, with comparable effects in patients with or without bone metastases. In the same manner, EV decreased the risk of progression by $12 \%$ compared to SO (adjusted HR 0.88 , $95 \% \mathrm{Cl} 0.82-0.96 ; p=0.002$ ), but this difference was not significant in patients without bone metastases. The major limitations of the study are its retrospective nature, the heterogeneity of the methods to detect bone metastases, and the lack of data about patients treated with bisphosphonates.

Conclusions: The relative benefit of targeted therapies in mRCC is not affected by the presence of bone metastases, but patients without bone metastases have longer response to therapy and overall survival.

\section{Introduction}

The skeleton is commonly affected by metastatic cancer. Genitourinary tumours, such as prostate and renal cell carcinoma (RCC), are particularly likely to spread to the bone. This represents the first and the fourth causes of bone metas- tases at post-mortem examination, with an incidence rate of $70 \%$ and $35 \%$ of cases, respectively. ${ }^{1}$ In renal cancer, bone metastases represent the second most common site of distant metastatic spread (after lung). ${ }^{2}$ Generally, the most frequent sites are pelvis, spine and ribs..$^{3-6}$ Skeletal involvement in RCC is an aggressive, lytic process causing significant morbidity from skeletal-related events (SREs). ${ }^{3}$ In mRCC, SREs have been related to decreased functional independence, loss of autonomy and decreased quality of life compared with bone metastases from other tumours.

During the last decade some targeted therapies have been approved for $\mathrm{mRCC}^{8}$ these can be classified as follows: (1) inhibitors of the vascular endothelial growth factor (VEGF) (i.e., bevacizumab in combination with interferon) or its receptor (VEGFR) (i.e., sorafenib, sunitinib, pazopanib, axitinib), and (2) mTOR inhibitors (mTORi) (i.e., temsirolimus and everolimus).

Current guidelines recommend VEGF/VEGFR inhibitors as first-line therapy and temsirolimus in poor-risk patients, while there is no univocal indication for mTOR or VEGFR inhibitors as subsequent lines. ${ }^{9-12}$ Given the increasing incidence of RCC, improvements in overall survival (OS) over the last decade, and the high rates of SRE in $\mathrm{MRCC}$ patients, a better knowledge of the efficacy of these agents in bone mRCC patients might help us select the best therapeutic sequence for our patients.

In patients treated with first-line tyrosine kinase inhibitor (TKI) sunitinib, bone metastases were significant and clinically relevant negative prognostic factors affecting progression-free survival (PFS) and OS, ${ }^{13}$ but effectiveness of targeted therapies in subsequent lines in patients with or without bone metastases has never been assessed.

We therefore investigate the clinical efficacy of these agents in patients with bone metastases by retrospectively analyzing the clinical outcomes in a selected group of patients who received third-line everolimus (EV) or sorafenib (SO) for mRCC. 
Iacovelli et al.

\section{Methods}

\section{Patients}

We retrospectively reviewed consecutive patients with clear cell mRCC treated with three lines of targeted therapies at 23 centres in Italy. To avoid bias due to different treatments, only patients who received EV or SO as third-line were included in the analysis. For each patient, we collected information on baseline characteristics, such as age, sex, date of nephrectomy, prognostic class based on the Heng criteria, ${ }^{14}$ and site of metastases at the beginning of the third-line treatment. Patients were analyzed based on type of treatment received and on the presence or absence of bone metastases.

All patients received standard dose EV or SO after two previous lines of targeted therapies; treatments were administered until disease progression or until the patient developed unacceptable levels of toxicity. Response assessment by computed tomography (CT) or magnetic resonance imaging (MRI) scans was carried out according to local procedures every 8 to 12 weeks and assessed locally by a radiologist. The progression of disease was defined as $a \geq 20 \%$ increase of the long diameter according to the RECIST 1.0 criteria. ${ }^{15}$ As reported by RECIST 1.0 criteria, bone metastases were not accepted as target lesions because they are non-measurable.

\section{Statistical analysis}

Statistics were only descriptive and values were expressed as median and interquartile range (IQR). PFS was defined as the time from beginning of treatment to progression or death from any cause, whichever occurred first. OS was defined as the time from start of third-line treatment to death or censored at last contact. PFS and OS were estimated using Kaplan-Meier method with 95\% confidence intervals $(\mathrm{Cl})$ and compared across groups using the log-rank test. The Chi-Square test and t-test were used to assess differences between groups whenever appropriate. Spearman test $\left(r_{s}\right)$ was used to asses any correlation between the BMs (yes or no) and type of therapy used (EV or SO). Survival analysis was adjusted for Heng prognostic criteria using Cox analysis. Statistical significance was set at $p<0.05$. PASW (Predictive Analytics SoftWare, v.18; IBM SPSS) was used.

\section{Results}

\section{General characteristics}

A total of $281 \mathrm{mRCC}$ patients treated with three lines of targeted therapies were screened. ${ }^{16}$ Of these, 233 patients received $\mathrm{EV}$ or $\mathrm{SO}$ as third-line and included in the final analysis. The median age was 63.2 years (IQR 55.7-70.9); $73.8 \%$ of patients were male, $96.1 \%$ had a radical nephrectomy, and $38.6 \%$ were metastatic at diagnosis. Regarding first-line therapy, $66 \%$ of patients received sunitinib, $19 \%$ $\mathrm{SO}$, and $10 \%$ bevacizumab plus interferon; the remaining $5 \%$ received other therapies. Second line was SO in 33\%, sunitinib in $31 \%$, everolimus in $25 \%$, and temsirolimus in $10 \%$ of patients.

In the overall population, the median OS was 13.8 months (95\% Cl 10.1-17.6); when stratified by Heng classification, the median OS was 24.3 months $(95 \% \mathrm{Cl} 14.3-34.2)$ in the good prognosis group, 13.8 months $(95 \% \mathrm{Cl} 10.2-17.4)$ in the intermediate group, and 5.5 months $(95 \% \mathrm{Cl} 2.2-8.9)$ in the poor prognostic group. The differences were statistically significant (good vs. intermediate $p=0.014$; intermediate vs. poor $p<0.001$ ).

\section{BMs and survival}

A total of 76 patients (32.6\%) had bone metastases at the beginning of third-line treatment. In these patients, the median OS was 10.4 months compared to 17.4 months in patients without bone metastases ( $p=0.002)$ (Fig. 1). Among patients with bone metastases, $18.7 \%$ had ECOG-PS=0, in $48.0 \%$ had Eastern Cooperative Oncology Group-Performance Status (ECOG-PS) 1 , and $33.3 \%$ had ECOG-PS 2; difference in the distribution of patients was significant when compared to patients without bone metastases (Table 1).

In the same group of patients $17.1 \%$ had good prognosis, $71.1 \%$ intermediate, and $11.8 \%$ poor prognosis based on the Heng criteria. The median survival for each group was 20.2, 9.7 and 4.7 months, respectively (good vs. intermediate $p=0.088$; intermediate vs. poor $p=0.001$ ). In patients without bone metastases, the good prognostic group had a median survival of 24.2 months compared with 17.4 and 7.8 months for intermediate and poor prognostic group, respectively (good vs. intermediate $p=0.21$; intermediate vs. poor $p=0.001)$.

\section{BMs and treatment outcome}

Of our study cohort, $143(61.4 \%)$ received EV and 90 $(38.6 \%)$ received SO; among the patients with bone metastases, $47(32.9 \%)$ received $\mathrm{EV}$ and $29(33.0 \%)$ received SO (Table 1).

No correlation was found between the type of treatment and the presence of bone metastases $\left(r_{s}=0.007, p=0.92\right)$. In the overall cohort, EV decreased the risk of death by $20 \%$ compared to SO (unadjusted HR 0.80, 95\% Cl 0.72-0.88, $p<0.001$ ); this result was confirmed when adjusted for the Heng criteria (adjusted HR 0.82, 95\% Cl 0.74-0.91, $p<0.001)$. When patients were divided by the presence 


\begin{tabular}{|c|c|c|c|c|}
\hline & \multirow{2}{*}{ All patients $(N=233)$} & \multicolumn{2}{|c|}{ Bone metastases } & \multirow{2}{*}{$\chi^{2}$ test $p$ value } \\
\hline & & Yes $n=76$ & No $n=157$ & \\
\hline Median age, years & $\begin{array}{c}63.2 \\
\text { (IOR 55.7-70.9) }\end{array}$ & $\begin{array}{c}61.8 \\
\text { (IOR 52.1-69.6) }\end{array}$ & $\begin{array}{c}60.7 \\
\text { (IOR 54.1-68.2) }\end{array}$ & 0.15 \\
\hline Male sex & $73.8 \%$ & $75.0 \%$ & $73.5 \%$ & 0.81 \\
\hline Metastatic at diagnosis & $38.6 \%$ & $47.4 \%$ & $34.8 \%$ & 0.07 \\
\hline Radical nephrectomy & $96.1 \%$ & $94.7 \%$ & 96.8 & 0.45 \\
\hline Heng' prognostic group & & & & 0.19 \\
\hline Good & $22.7 \%$ & $17.1 \%$ & $25.2 \%$ & \\
\hline Intermediate & $69.1 \%$ & $71.1 \%$ & $68.4 \%$ & \\
\hline Poor & $8.2 \%$ & $11.8 \%$ & $6.5 \%$ & \\
\hline Treatment (SO/EV) & $38.6 \% / 61.4 \%$ & $38.2 \% / 61.8 \%$ & $38.9 \% / 61.1 \%$ & 0.99 \\
\hline Sites of metastases $\geq 2$ & $86.2 \%$ & $92.1 \%$ & $83.9 \%$ & 0.085 \\
\hline ECOG-PS & & & & $<0.001$ \\
\hline 0 & $28.4 \%$ & $18.7 \%$ & $33.5 \%$ & \\
\hline 1 & $52.6 \%$ & $48.0 \%$ & $54.8 \%$ & \\
\hline 2 & $19.0 \%$ & $33.3 \%$ & $11.6 \%$ & \\
\hline
\end{tabular}

of less bone metastases, the effect of EV over SO was comparable; the adjusted HR in patients without bone metastases was $0.82(95 \% \mathrm{Cl} 0.72-0.93, p=0.002)$ and 0.84 $(95 \% \mathrm{Cl} 0.71-0.98, \mathrm{p}=0.029)$ in patients with bone metastases (Table 2).

EV decreased the risk of progression by $12 \%$ compared to $\mathrm{SO}$ (unadjusted HR $0.88,95 \% \mathrm{Cl} 0.81-0.95, p=0.001$ ); this result was confirmed when adjusted for the Heng criteria (adjusted HR 0.88, 95\% Cl 0.82-0.96, $p=0.002$ ). When patients were divided by the presence of less of bone metastases, patients treated with EV lived longer. The adjusted HR in patients without bone metastases was $0.88(95 \% \mathrm{Cl} 0.80$ $0.97, p=0.010)$ and $0.89(95 \% \mathrm{Cl} 0.77-1.03, p=0.12)$ in patients with bone metastases (Table 3).

\section{Multivariable analysis}

On univariable analysis, predictors of OS included the Heng' prognostic criteria, the presence of bone metastases, the number of metastatic sites and the type of third-line medication administered. Multivariable analysis confirmed this, with the exclusion of the number of metastatic sites (Table 4).

\section{Discussion}

To our knowledge, this is the first multicentre survey to investigate the effectiveness of targeted therapies related to bone metastases in patients who received third-line therapy for mRCC. In this retrospective analysis, only patients treated with third-line SO or EV were included. We were able to show that: (1) the presence of bone metastases is an independent negative prognostic factor; and (2) the presence of bone metastases is closely related to a worsening performance status. On the other hand, prognostic category is not affected, likely because it is based on other clinical and biochemical factors other than ECOG-PS.

This evidence is consistent with previous studies reporting a negative impact of skeletal disease on survival in mRCC patients. ${ }^{17}$ Bianchi and colleagues found that a greater incidence of bone metastases was related to the thoracic extension of tumour spread; this was $10 \%$ in patients with exclusive abdominal metastases and $49 \%$ in patients with abdominal, thoracic, and brain metastases. ${ }^{18}$

Our study shows the adverse prognostic role of bone metastases during the advanced phases of disease when patients have received more lines of therapy; we also report that bone metastases did not affect the activity of EV over SO. In fact, the decreased risk of death was comparable in

\begin{tabular}{|c|c|c|c|c|c|c|c|c|}
\hline \multirow[b]{2}{*}{ Patients } & \multicolumn{3}{|c|}{ Everolimus } & \multicolumn{3}{|c|}{ Sorafenib } & \multirow[b]{2}{*}{ HR (95\% Cl) } & \multirow[b]{2}{*}{$p$ value } \\
\hline & No. patients & $\begin{array}{l}\text { Median OS, } \\
\text { months }\end{array}$ & $95 \% \mathrm{Cl}$ & No. patients & $\begin{array}{l}\text { Median OS, } \\
\text { months }\end{array}$ & $95 \% \mathrm{Cl}$ & & \\
\hline Without BMs & 96 & 20.2 & $12.6-27.7$ & 61 & 10.1 & $7.2-13.1$ & $0.80(0.70-0.91)$ & 0.001 \\
\hline With BMs & 47 & 13.2 & $7.2-19.2$ & 29 & 6.9 & $3.2-10.5$ & $0.82(0.70-0.97)$ & 0.017 \\
\hline
\end{tabular}


Iacovelli et al.

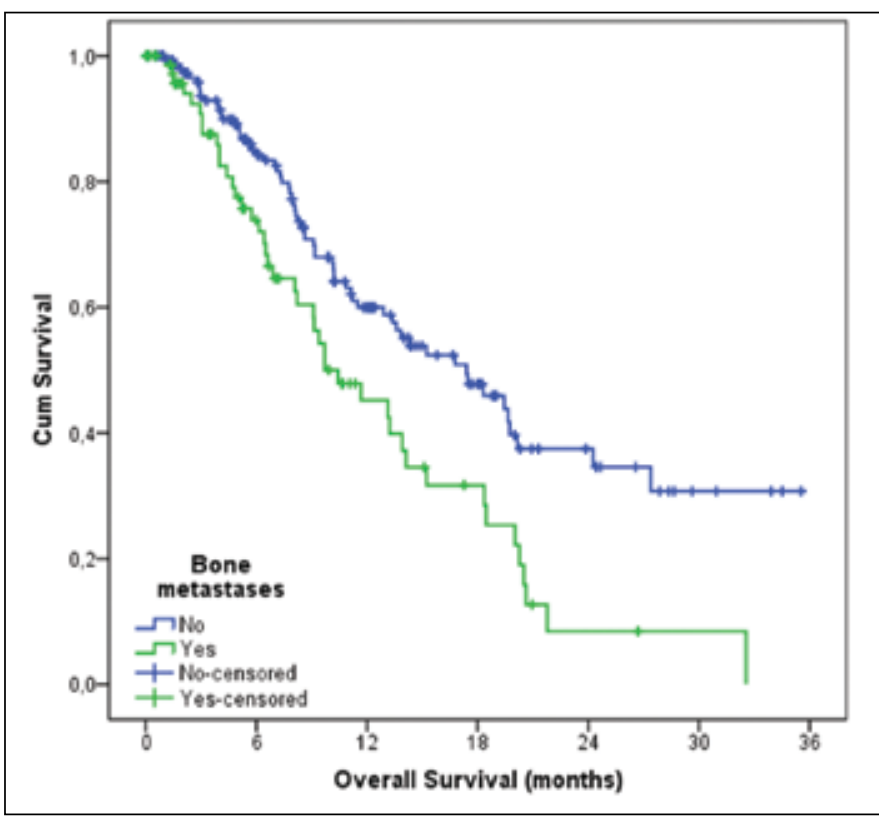

Fig. 1. Overall survival based on presence of bone metastases.

patients with or without bone metastases even if the absolute values of OS were shorter in patients with bone metastases. Therefore, the reported superiority of EV over SO should be read with caution mainly because results are not based on prospective trials.

Our study has its limitations. Firstly, its retrospective nature limits data accuracy; however, the types of patients included represent a typical real-case scenario. Secondly, the heterogeneity of the methods used to detect bone metastases may lead to inaccurate data distribution; each technique has its own limits. Thirdly, we were unable to report the rate of patients who received bisphosphonate and to estimate its impact on prognosis. Other limitations were the lack of central review of disease progression, the lack of patients treated with the newer VEGFR-TKI axitinib, and the small cohort of patients with bone metastases.

There is no definitive data on the role of bisphosphonates to treat bone metastases from $\mathrm{mRCC}$. In their subgroup analysis of 74 patients with mRCC, Lipton and colleagues found that zoledronic acid extended the time to the first event and reduced the risk of SRE by $61 \%$ compared to placebo (HR 0.394, $p=0.008) .{ }^{19}$ In a recent retrospective analysis on 76 patients affected by $\mathrm{mRCC}$ and all treated with suni- tinib, 35 received bisphosphonate and 41 were non-users. In the treated group, the bisphosphonate decreased the risk of progression by $45 \%(\mathrm{HR} 0.55, p<0.001)$ and of the risk of death by $60 \%$ (HR 0.4, $p=0.029) .{ }^{20}$ Even if zoledronic acid has been reported to reduce the risk of SREs in these patients, ${ }^{21}$ the benefit of this treatment needs to be balanced by the reported increase of risk of the osteonecrosis of the jaw, especially when the bisphosphonate is co-administered with an antiangiogenic agent. ${ }^{22}$

The Heng criteria were used in the present analysis, even if they have never been validated in a third-line setting. As such, we were able to discriminate three populations with different outcomes.

Patients with bone metastases should be treated in a multidisciplinary context to improve survival, quality of life, and to decrease psychophysical suffering. ${ }^{23}$

\section{Conclusion}

The relative benefit of targeted therapies in mRCC is not affected by the presence of bone metastases, but patients without bone metastases have longer response to therapy and overall survival.

Competing interests: The authors declare no competing financial or personal interests.

This paper has been peer-reviewed.

\section{References}

1. Galasko C. The anatomy and pathways of skeletal metastases. In: Bone Metastases. Weiss L, Gilbert A, editors. GK Hall, Boston; 1981:49-63.

2. Woodward E, Jagdev S, McParland L, et al. Skeletal complications and survival in renal cancer patients with bone metastases. Bone 2011;48:160-6. http://dx.doi.org/10.1016/i.bone.2010.09.008

3. Zekri J, Ahmed N, Coleman RE, et al. The skeletal metastatic complications of renal cell carcinoma. Int J Oncol 2001;19:379-82. http://dx.doi.org/10.3892/iij.19.2.379

4. Althausen $P$, Althausen $A$, Jennings $L C$, et al. Prognostic factors and surgical treatment of osseous metastases secondary to renal cell carcinoma. Cancer 1997;80:1103-9. http://dx.doi.org/10.1002/ (SICI) 1097-0142(19970915) 80:6<1 103::AID-CNCR13>3.0.C0;2-C

5. Koga $S$, Tsuda $S$, Nishikido $M$, et al. The diagnostic value of bone scan in patients with renal cell carcinoma. J Urol 2001;166:2126-8. http://dx.doi.org/10.1016/S0022-5347(05)65519-X

6. Santini D, Procopio $G$, Porta $C$, et al. Natural history of malignant bone disease in renal cancer: Final results of an Italian bone metastases survey. J Clin Oncol 2012;30(Suppl; abstr 4627).

7. Smith MR. Zoledronic acid to prevent skeletal complications in cancer: Corroborating the evidence. Cancer Treat Rev 2005;31 (Suppl 3):19-25. http://dx.doi.org/10.1016/i.ctrv.2005.09.004

\begin{tabular}{|c|c|c|c|c|c|c|c|c|}
\hline \multirow[b]{2}{*}{ Patients } & \multicolumn{3}{|c|}{ Everolimus } & \multicolumn{3}{|c|}{ Sorafenib } & \multirow[b]{2}{*}{ HR (95\% CI) } & \multirow[b]{2}{*}{$p$ value } \\
\hline & No. patients & $\begin{array}{c}\text { Median PFS, } \\
\text { months }\end{array}$ & $95 \% \mathrm{Cl}$ & No. patients & $\begin{array}{c}\text { Median PFS, } \\
\text { months }\end{array}$ & $95 \% \mathrm{Cl}$ & & \\
\hline Without BMs & 96 & 7.1 & $5.1-9.0$ & 61 & 5.2 & $4.0-6.4$ & $0.88(0.80-0.97)$ & 0.008 \\
\hline With BMs & 47 & 6.8 & $4.0-9.5$ & 29 & 3.8 & $1.8-5.8$ & $0.87(0.76-1.01)$ & 0.066 \\
\hline
\end{tabular}




\section{Table 4. Univariate and multivariable Cox analysis for overall survival}

\begin{tabular}{|c|c|c|c|c|}
\hline \multirow{2}{*}{ os } & \multicolumn{2}{|c|}{ Univariate Cox regression } & \multicolumn{2}{|c|}{ Multivariable Cox regression } \\
\hline & HR (95\% Cl) & $p$ value & HR (95\% Cl) & $p$ value \\
\hline \multicolumn{5}{|l|}{ Heng prognostic group } \\
\hline Good vs. poor & $0.15(0.07-0.31)$ & $<0.001$ & $0.17(0.08-0.37)$ & $<0.001$ \\
\hline Intermediate vs. poor & $0.28(0.16-0.53)$ & $<0.001$ & $0.27(0.15-0.50)$ & $<0.001$ \\
\hline $\mathrm{BM}(\mathrm{Y} / \mathrm{N})$ & $1.84(1.25-2.72)$ & 0.002 & $1.81(1.21-2.70)$ & 0.003 \\
\hline Sites of metastases $\geq 2(\mathrm{Y} / \mathrm{N})$ & $1.72(0.92-3.23)$ & 0.088 & & \\
\hline Therapy (SO vs. EV) & $2.43(1.65-3.63)$ & $<0.001$ & $2.21(1.47-3.31)$ & $<0.001$ \\
\hline
\end{tabular}

OS: overall survival; BM: bone metastases, Cl: confidence interval; HR: hazard ratio; Y: yes; N: no; EV: everolimus; SO: sorafenib.

8. Palazzo A, lacovelli R, Cortesi E. Past, present and future of targeted therapy in solid tumors. Curr Cancer Drug Targets 2010;10:433-61. http://dx.doi.org/10.2174/156800910791517145

9. National Comprehensive Cancer Network (NCCN) guidelines. www.nccn.org. Accessed July 3, 2015

10. European Society of Medical Oncology (ESMO) guidelines. www. esmo.org. Accessed July 3, 2015.

11. Iacovelli R, Palazzo A, Trenta P, et al. Management of metastatic renal cell carcinoma progressed after sunitinib or another antiangiogenic treatment. Am J Clin Oncol 2014;37:611-5. Epub 2013 Feb 5. http://dx.doi.org/10.1097/COC.0b013e31827de888

12. Procopio $G$, Verzoni E, Guadalupi $V$, et al. Is it possible to optimize the use of targeted therapies in the treatment of renal cell carcinoma? Tumori 2010;96:794-5.

13. Beuselinck $B$, Oudard $S$, Rixe 0 , et al. Negative impact of bone metastasis on outcome in clear-cell renal cell carcinoma treated with sunitinib. Ann Oncol 2011;22:794-800. http://dx.doi.org/10.1093/ annonc/mdq554

14. Heng DY, Xie W, Regan MM, et al. Prognostic factors for overall survival in patients with metastatic renal cell carcinoma treated with vascular endothelial growth factor-targeted agents: Results from a large, multicenter study. J Clin Oncol 2009;27:5794-9. http://dx.doi.org/10.1200/JC0.2008.21.4809

15. Therasse $\mathrm{P}$, Arbuck SG, Eisenhaver EA, et al. New guidelines to evaluate the response to treatment in solid tumors. European Organization for Research and Treatment of Cancer, National Cancer Institute of the United States, National Cancer Institute of Canada. J Natl Cancer Inst 2000;92:205-16. http:// dx.doi.org/10.1093/inci/92.3.205

16. lacovelli R, Cartenì G, Sternberg $C N$, et al. Clinical outcomes in patients receiving three lines of targeted therapy for metastatic renal cell carcinoma: Results from a large patient cohort. Eur $J$ Cancer 2013;49:2134-42. http://dx.doi.org/10.1016/.iejca.2013.02.032

17. Beuselinck $B$, Oudard $S$, Rixe 0 , et al. Negative impact of bone metastasis on outcome in clear-cell renal cell carcinoma treated with sunitinib. Ann Oncol 2011;22:794-800. http://dx.doi.org/10.1093/ annonc/mdq554
18. Bianchi $M$, Sun $M$, Jeldres $C$, et al. Distribution of metastatic sites in renal cell carcinoma: A population-based analysis. Ann Oncol 2012;23:973-80. http://dx.doi.org/10.1093/annonc/mdr362

19. Lipton $A$, Zheng $M$, Seaman J. Zoledronic acid delays the onset of skeletal-related events and progression of skeletal disease in patients with advanced renal cell carcinoma. Cancer 2003;98:962-9. http:// dx.doi.org/10.1002/cncr.11571

20. Keizman D, Ish-Shalom M, Pili R, et al. Bisphosphonates combined with sunitinib may improve the response rate, progression free survival and overall survival of patients with bone metastases from renal cell carcinoma. Eur J Cancer 2012;48:1031-7. http://dx.doi.org/10.1016/i.ejca.2012.02.050

21. Tunn UW, StenzI A, Schultze-Seemann W, et al. Positive effects of zoledronate on skeletal-related events in patients with renal cell cancer and bone metastases. Can J Urol 2012;19:6261-7.

22. Christodoulou $C$, Pervena $A$, Klouvas $G$, et al. Combination of bisphosphonates and antiangiogenic factors induces osteonecrosis of the jaw more frequently than bisphosphonates alone. Oncology 2009;76:209-11. http://dx.doi.org/10.1159/000201931

23. Ibrahim T, Flamini E, Fabbri L, et al. Multidisciplinary approach to the treatment of bone metastases: Osteo-Oncology Center, a new organizational model. Tumori 2009;95:291-7.

Correspondence: Dr. Roberto lacovelli, Sapienza University of Rome; Department of Radiology, Oncology and Human Pathology, Oncology Unit B. Viale Regina Elena 324, 00161 Rome, Italy; roberto.iacovelli@alice.it 